\title{
CRESCIMENTO URBANO DESORDENADO DO COMPLEXO FREI CALIXO - BAIANÃO, PORTO SEGURO - BA: UM ESTUDO DA DEGRADAÇÃO DOS MANANCIAIS
}

\section{ARTIGO ORIGINAL}

ROCHA, Wilson da Silva ${ }^{1}$

ROCHA, Wilson da Silva. Crescimento urbano desordenado do Complexo Frei Calixo - Baianão, Porto Seguro - BA: um estudo da degradação dos mananciais. Revista Científica Multidisciplinar Núcleo do Conhecimento. Ano. 06, Ed. 12, Vol. 10, pp. 17-29. Dezembro de 2021. ISSN: 2448-0959, Link de acesso: https://www.nucleodoconhecimento.com.br/meio-ambiente/crescimento-

\section{urbano-desordenado}

\section{RESUMO}

O presente trabalho analisou os impactos ambientais do processo de urbanização do Complexo Baianão no município de Porto Seguro - BA, a partir do intenso fluxo migratório causado pela crise econômica da região cacaueira, afetada pela vassoura de bruxa na década de 1990. Esse fator originou o surgimento acelerado de um complexo de bairros em Área de Preservação Permanente, comprometendo a sustentabilidade dos mananciais, principalmente o que abastece a população local. Outro ponto levantado nessa investigação, é a ausência de políticas públicas no uso e ocupação do solo de forma sustentável, demonstrando uma fragilidade no ordenamento urbano, forçando uma parcela desses migrantes a ocuparem espaço de encostas, gerando assim, impactos socioambientais. A urbanização rápida, sem o devido gerenciamento urbano ecológico e econômico da área em estudo tem se

${ }^{1}$ Pós-graduando em Educação Ambiental e Sustentabilidade. ORCID: 0000-00016745-1146

RC: 103964

Disponível em: https://www.nucleodoconhecimento.com.br/meio-ambiente/crescimentourbano-desordenado 
mostrado como um dos principais problemas ambientais e de zoneamento das áreas ocupadas. A problemática desse estudo, surgiu a partir de dois fatores: Da urbanização e crescimento acelerado do Complexo do Baianão em Área de Preservação Permanente, comprometendo a sustentabilidade dos mananciais, principalmente o que abastece a população local. O segundo fator, consiste na ausência de acervos científicos sobre essa temática. Para a realização desta pesquisa qualitativa, utilizou-se fontes bibliográficas que tratam da referida temática, incluindo legislações ambientais, o processamento de imagens de satélites da região investigada através do software Qgis 3.12 e atividade de campo. Os resultados desta pesquisa apontaram lacunas nas políticas públicas que norteiam o uso e ocupação de áreas urbanas desse complexo de bairros. Nesse sentido, considera-se relevante essa temática, pois propicia novos olhares e questionamentos sobre crescimento urbano desordenado vem comprometendo os sistemas naturais frágeis e vazão hídrica no município de Porto Seguro - BA.

Palavras-chave: Mananciais, Degradação Ambiental, Políticas Públicas, Crescimento Urbano.

\section{INTRODUÇÃO}

O processo de crescimento urbano acelerado de Porto Seguro está atrelado à transformação da cidade por um grande polo turístico. Iniciando com a construção da BR-364, ramal da BR-101 no ano de 1974, através da "criação do Plano Diretor da Orla Marítima de Porto Seguro e Santa Cruz Cabrália. Tratando-se, da primeira tentativa de se regular o uso e ocupação do solo no município" (CARVALHO, 2008, p. 02).

Nessa percepção, Araújo (2004, p. 145-146) afirma que, a partir da consolidação de Porto Seguro como polo turístico do Brasil, "o município passa a ser visto como uma zona de oportunidades de emprego". Intensificando-se a partir da década de 1990, com a crise da vassoura de bruxa na região cacaueira da Bahia, o fluxo migratório.

RC: 103964

Disponível em: https://www.nucleodoconhecimento.com.br/meio-ambiente/crescimentourbano-desordenado 
Nesse Sentido, o município passa a ser área de atração populacional de várias regiões do Brasil, e, principalmente, do extremo sul da Bahia.

De acordo com Araújo (2004), o processo de formação do Complexo Baianão se deu a partir da invasão ao longo de terras próximo à rodovia 367, ocupação incentivada por político local em áreas ambientalmente frágeis. Desmatando florestas, ocupando cabeceiras de rios, córregos e encostas, causado por políticas suprimidas de uso de ocupação do solo.

Dessa maneira, as políticas urbanas de uso e ocupação do solo, são despercebidas de ações socioambientais, visto que são doutrinadas aos interesses capitalistas, gerando segregação espacial e degradação do meio ambiente em nosso país, conforme menciona Ribas (2003). A expansão urbana um município de Porto Seguro - BA tem negligenciado as áreas de proteção ambiental, o que tem levado ao agravamento notório de problemas ambientais.

Nos nossos estudos, também verificou - se que a esse processo de urbanização desordenado gerou segregação socioeconômica, levando muitos imigrantes a ocuparem Áreas de Proteção Ambiental (APP), impulsionando uma retroalimentação negativa ambiental e social.

[. . .] os instrumentos da política ambiental, por não terem sido estruturados com a lógica do ordenamento territorial que caracteriza o gerenciamento urbano, e sim das intervenções pontuais para controle e mitigação de atividades, encontram- se distantes das reais necessidades de enfrentamento dos problemas urbanos (RIBAS, 2003, p. 113).

Para Guerra e Cunha (2007), as falhas no ordenamento urbano, pode gerar um sistema socioambiental de retroalimentação negativa, ou seja, a vulnerabilidade social dessas pessoas ocasiona degradação ambiental, alimentando o ciclo de pobreza. A expansão urbana do Complexo do Baianão tem provocado impactos ambientais, como assoreamento de rios e córregos, deslizamento do solo em terrenos acidentados, poluição dos rios e redução da biodiversidade local.

RC: 103964

Disponível em: https://www.nucleodoconhecimento.com.br/meio-ambiente/crescimentourbano-desordenado 
A problemática deste estudo surge de alguns fatores importantes, primeiro por ser um complexo de bairros que surgiu da ocupação de imigrantes. Migração impulsionada pela crise da vassoura de bruxa na região cacaueira do sul da Bahia em 1990. O segundo fator se fundamenta por se tratar de um conjunto de bairros que teve sua expansão em áreas de cursos d'águas, terrenos arenosos e encostas. Áreas de proteção ambiental inapropriadas para moradias urbanas, sendo principalmente ocupadas por pessoa de origem humilde.

Dessa forma, a questão em foco, nesta pesquisa, é investigar, compreender e analisar a degradação dos mananciais in loco pelo processo de ocupação e expansão urbana a partir de 1990 no município de Porto Seguro - BA. Ressaltando a importância de aplicabilidade das políticas públicas de ocupação de solos urbanos, visando ações para atenuar e prevenir a evolução da degradação ambiental nesse conjunto de bairros.

A metodologia adotada neste trabalho é cunho qualitativo mediante o procedimento do estudo de caso, bibliográfico e documental. Seu escopo metodológico é de caráter explicativo, enfatizando os impactos ambientais nos mananciais submetidos pelo crescimento urbano desordenado do Complexo Baianão no município de Porto Seguro - Ba dos últimos 29 anos.

Neste sentido a metodologia do trabalho foi organizada em duas etapas de estudos exploratórios. A primeira consistiu em uma revisão bibliográfica de obras científicas e legislações ambientais, que abordam o ordenamento de uso e ocupação dos solos em Áreas de Preservação Permanente - APP e referências do processo de ocupação e formação deste complexo de bairros em estudo.

No segundo momento, procedeu-se no uso do Sistema de Informação Geográfica (QGis 3.16.2), arquivos tipo Shipefile e imagens de satélite para a construção da base cartográfica das imagens usadas na área de estudo. Foram utilizadas escalas de

RC: 103964

Disponível em: https://www.nucleodoconhecimento.com.br/meio-ambiente/crescimentourbano-desordenado 
1:1000.000 e 1:100.000, com as seguintes referências cartográficas: EPSG:4674 SIRGAS 2000.

No mapeamento, utilizou - se imagens LANDSAT e, composição colorida nas bandas $1,2,5,7)$, respectivamente. Após o geoprocessamento da área estudada, foram identificados os principais cursos d'água e sua extensão. Com relação ao anatropismo, foi adotada a classe de urbanização.

\section{DESENVOLVIMENTO}

Constitui-se a área de estudo deste trabalho o Complexo de bairros Frei Calixto Baianão no município de Porto Seguro, que encontra-se inserido na Mesorregião Sul da Bahia (IBGE, 2019). O perímetro pesquisado trata-se de um espaço de $14,9 \mathrm{~km}^{2}$ na porção nordeste da cidade próximo a BR 376 , tendo como mosaico vegetacional florestas ombrófilas densas recortadas por curso d'águas que formam a principal rede hidrográfica local.

RC: 103964

Disponível em: https://www.nucleodoconhecimento.com.br/meio-ambiente/crescimentourbano-desordenado 
Figura 1 - Delimitação da área de estudo

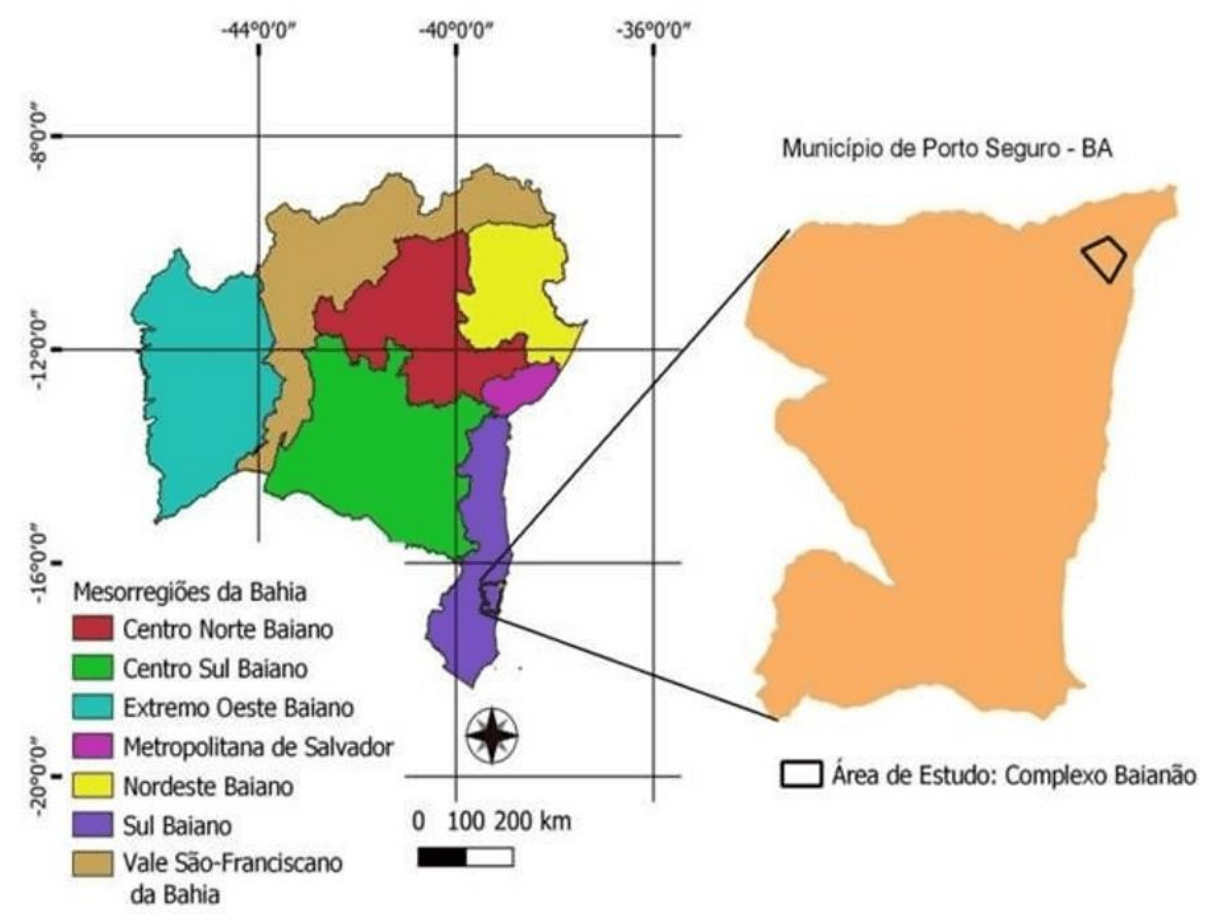

Fonte: IBGE, 2019.

A Fundação do complexo de bairros é datada do início de 1990, de acordo com o Baianão (2013), os moradores já residentes na cidade eram contra a construção e desenvolvimento urbano nesta área, pois, tratava-se de migrantes humildes das lavouras na região cacaueira baiana, atrás de oportunidades de trabalho gerado pelo setor turístico.

Os primeiros moradores da área em estudo encontraram serviço, mas não direito a cidade, corroborando com os argumentos apresentados, Araújo (2005) afirma que esse crescimento urbano desordenado está relacionado à omissão de ações que abrigasse esse contingente populacional em locais apropriados.

Desta forma, começou a construção dos primeiros barracos, erguidos no espaço florestado de Mata Atlântica cortada por rios e córregos, conforme descrito na figura 02. Assim, podemos inferir que o espaço estudado possui uma grande diversidade RC: 103964

Disponível em: https://www.nucleodoconhecimento.com.br/meio-ambiente/crescimentourbano-desordenado 
hidrológica e, coadunando a essa assertiva, a Veracel (2011) apresenta os seguintes dados.

\begin{abstract}
Porto Seguro destaca-se por uma enorme riqueza de recursos hídricos. Prática- mente em todos os pequenos vales do município há nascentes e cursos d'água, e no território do município encontram-se 22 microbacias hidrográficas. A quase totalidade dos rios e córregos que drenam o município possui vales longos e aprofundamento médio variável, mas normalmente superior a 20 metros, e talvegues de fundo chatos preenchidos por aluviões. O padrão de drenagem observado para os cursos d'água que ocorrem na região dos tabuleiros costeiros é nitidamente dendrítico1 para os tributários de segunda ordem e preferencialmente paralelo para os cursos principais, onde observa se certo paralelismo entre as calhas fluviais, todos drenando a área em sentido oeste-leste. Este padrão parece ser fruto apenas do controle topográfico imposto pela suave e contínua inclinação dos tabuleiros em direção leste (VERACEL, 2011, online).
\end{abstract}

Diante do exposto, a construção do Complexo Baianão ocorreu em um espaço delimitado por várias APA, com a supressão de um zoneamento urbano sustentável, por tratar-se de uma área regulamentada pelo código Florestal Brasileiro em seu artigo $\left(4^{\circ}\right)\left(\right.$ Lei $\left.n^{\circ} 12.651,2012\right)$. $E$, em três décadas esse pequeno agrupamento urbano transformou - se em um complexo com suas subdivisões, conforme menciona a prefeitura local.

Com o crescimento do bairro foi surgindo as divisões: Mercado do povo, Casas novas, Nilo fraga, Boqueirão, Paraguai, Areião, Parque Ecológico, Vila Vitória, Porto Alegre I e II. Além de várias praças: Praça Murici, praça do Gravata, praça da caixa d'agua, praça do coelho, praça São João, entre outras. (PREFEITURA DE PORTO SEGURO, 2021, Online).

Diante do crescimento urbano acelerado, o Plano Diretor Municipal é reformulado através da lei nº 1511/19 estabelecendo políticas públicas participativas na promoção de eixos de qualificação ambiental e social, conforme menciona o Art. 17 inciso I.

Promoção do desenvolvimento social, econômico e cultural baseado na sustentabilidade e na conservação da Mata Atlântica, atendendo às diretrizes e ações estabelecidas no plano municipal de Conservação e Recuperação da Mata Atlântica do Município de Porto Seguro;[...] Parágrafo único: São ações estratégicas do eixo de

RC: 103964

Disponível em: https://www.nucleodoconhecimento.com.br/meio-ambiente/crescimentourbano-desordenado 
Qualificação Ambiental cuja a implementação deverá buscar: I - acompanhamento do plano de Recuperação das Áreas Degradadas do município, garantindo a recomposição das matas ciliares e preservação paisagísticas das falésias, bordas dos tabuleiros e faixa costeira. (PORTO SEGURO, 2019, n.p., grifo do autor).

Entretanto, a lei 1511/19 permanece apenas como diretrizes técnicas, visto que não é observado ações públicas ou privadas que busquem desenvolver mecanismo socioambientais de uso e ocupação dos solos urbanos engajados no Zoneamento Ecológico - Econômico e no Plano Diretor Municipal.

Assim, a expansão urbana do Complexo do Baianão nos últimos 30 anos e a inefetividade de ações visando o ordenamento urbano sustentável vem pressionando as áreas de preservação ambiental, como os mananciais existentes no território (Figura 02).

Figura 2 - Antropismo na hidrografia do município de Porto Seguro - BA

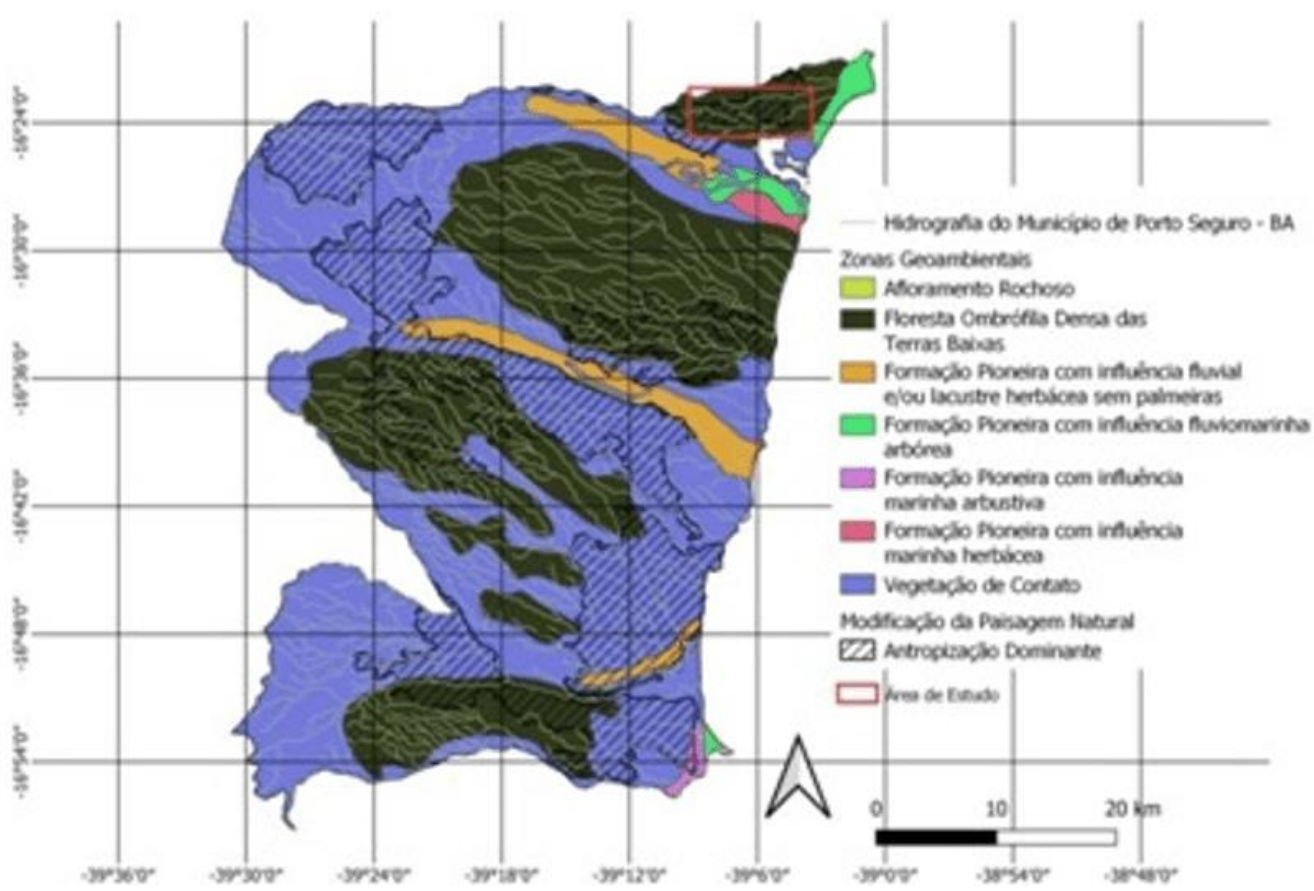

Fonte: IBGE, 2017.

RC: 103964

Disponível em: https://www.nucleodoconhecimento.com.br/meio-ambiente/crescimentourbano-desordenado 
Nesse sentido, Marroni e Asmus (2005), enfatiza que a elaboração de políticas de gerenciamento integrada é uma das condições prévias fundamentais para a elaboração de ações destinadas ao ordenamento urbano e a conservação ambiental. Assim, é preciso de conhecimentos socioambientais basilares, conforme afirma Townsend et al. (2010).

Os ecossistemas naturais têm sido ameaçados por um conjunto de influências humanas, principalmente em decorrência de nosso crescimento populacional explosivo. [...] Precisamos levar em consideração a extensão do problema, entender as ameaças impostas pelas atividades humanas e considerar como o conhecimento ecológico pode contribuir para a solução dos problemas ambientais. (TOWNSEND et al., 2010, p. 576).

O quadro de desgaste ambiental dos córregos e rios do perímetro estudado, levam à reflexão a limitação de ações voltadas a preservação dos mananciais. Nessa Concepção, Marroni e Asmus (2005) enfatiza que o avanço dos impactos socioambientais estão relacionados às mudanças do espaço natural, o que foi feito sem um ordenamento urbano integrado ao desenvolvimento sustentável, provocando degradação ambiental.

O Código Florestal Brasileiro no art. $3^{\circ}$ início II, regulamenta a proteção da vegetação situada nas áreas de preservação permanente, que incluem margens de rios, entorno de nascentes, encostas de alta declividade e topos de morros. Conforme dados publicados pelo Plano Municipal de Recuperação da Mata Atlântica - PMMA, os rios e córregos do município são classificados como área de Proteção Ambiental.

Entretanto, o gerenciamento de políticas públicas socioambientais na urbanização do Complexo do Baianão é inoperante, contribuindo o para acelerar o quadro de desgaste social e ambiental, haja vista que o zoneamento urbano adotado não contempla o viés sustentável, sem um projeto de ações que vise mitigar e preservar as matas ciliares da área em estudo.

RC: 103964

Disponível em: https://www.nucleodoconhecimento.com.br/meio-ambiente/crescimentourbano-desordenado 
Para Crispim et al. (2014, p.01), "O processo de urbanização, por ter caráter coletivo, enseja a responsabilidade do Estado como agente regulador, fiscalizador e principalmente planejador". Nesse sentido, percebe-se um olhar reflexivo sobre o antropismo nesses espaços, criando medias que visem à sustentabilidade do uso $\mathrm{e}$ ocupação do solo, a exemplo do zoneamento ecológico - econômico - ZEE.

Art. 6-A. O ZEE para fins de reconhecimento pelo Poder Público Federal deverá gerar produtos e informações nas seguintes escalas:[...] III - nas escalas locais de 1:100.000 e maiores, para indicativos operacionais de gestão e ordenamento territorial, tais como, planos diretores municipais, planos de gestão ambiental e territorial locais, usos de Áreas de Preservação Permanente, nos termos do art. 4을 Lei no 4.771, de 1965. [...]. Art. 11. O ZEE dividirá o território em zonas, de acordo com as necessidades de protecãa, conservacãa e recuperacãa dos recursos naturais e do desenvolvimento sustentável. [...]. Art. 13. O diagnóstico a que se refere o inciso I do art. 12 deverá conter, no mínimo: [...] III -Fragilidade Natural Potencial, definida por indicadores de perda da biodiversidade, vulnerabilidade natural à perda de solo, quantidade e qualidade dos recursos hídricos superficiais e subterrâneos. (Brasil, 2002, online, grifo do autor).

Assim, o Zoneamento Ecológico-Econômico (ZEE) propicia compreender a espacialidade das características ambientais, econômicas e culturais, surgindo como uma ferramenta normativa das questões ambiental e urbana (RIBAS, 2003). Dessa forma, o ZEE como ferramenta de análise do gerenciamento urbano no Complexo Baianão, que subsidia- ria a problemática de adensamento urbano, no desenvolvimento de ações socioambientais compensatórias e preventivas.

Entendendo como ocorreu a expansão urbana deste complexo de bairro, e qual sua tendência de crescimento é possível compreender e analisar os problemas ambientais causados devido a esse crescimento, visto que, a expansão urbana vem provocando uma forte pressão nos mananciais, em especial ao relacionado ao abastecimento de água do município. Na Figura 03 é possível constatar a evolução urbana sobre as áreas dos mananciais locais.

RC: 103964

Disponível em: https://www.nucleodoconhecimento.com.br/meio-ambiente/crescimentourbano-desordenado 
Figura 3 - Evolução da evolução do Complexo Baianão
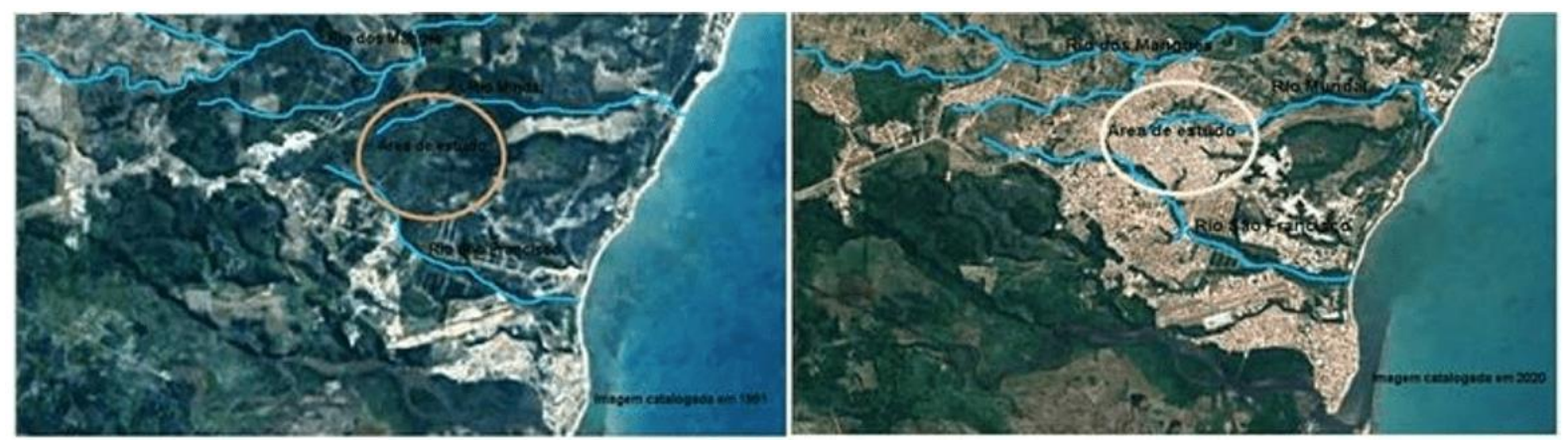

Fonte: Google Earth, 2021.

Considerando os dados apresentados na figura 03 , verifica - se que a área em estudo apresenta uma tendência de expansão urbana com alta concentração demográfica, e de acordo com Araújo (2004) a especulação imobiliária junto da exclusão socioeconômica tem levado as pessoas com menores rendas a ocuparem área de proteção ambiental.

O conjunto de problemas, econômicos, sociais e ambientais associados à expansão da área em estudo de maneira geral acarretam desmatamento de vegetação nativa, ocupação de cabeceiras de rios, córregos e encostas, vinculadas a carência de políticas de uso de ocupação do solo sustentável. Tais problemas, já afetam o principal Rio municipal, conforme descreve o PMMA (2014).

Rio dos Mangues: Maior rio municipal; abastece a cidade de Porto Seguro; área de atuação do CEPOC legal (MDPS); apresenta horto orestal criado por lei; grande investimento da EMBASA na recuperação da mata ciliar; apresenta PSA na bacia; a foz mantém o maior mangue da orla norte; Imbiruçu de dentro - Águas do Porto. Potencial paisagístico na periferia da cidade; potencial para área protegida; educação ambiental; viveiro de mudas; água potável; parcerias com entidades (EMBASA, ONGs, MDPS, SEMA, proprietários rurais, reserva da Jaqueira). Pontos Negativos: Esgoto doméstico; degradação da mata ciliar; expansão urbana (incluindo invasões indígenas); degradação da restinga; brejos litorâneos na foz. (PMMA, 2014, p.76).

RC: 103964

Disponível em: https://www.nucleodoconhecimento.com.br/meio-ambiente/crescimentourbano-desordenado 
Corroborando com essa temática, Ab'saber (2003) justifica que é necessário conhecer melhor as limitações de uso específico de cada paisagem, pois, é fundamental obter conhecimento mais racional desse espaço para a preservação do equilíbrio do meio ambiente.

Assim, o planejamento socioambiental regula e controla as atividades dos indivíduos e grupos, em que os efeitos negativos, que porventura possam surgir, sejam minimizados e, por conseguinte, promovam um melhor proveito do meio físico. Ao conhecer os cenários da evolução da paisagem ao longo do tempo, possibilita-se entender o passado, permitindo compreender o presente e indicar tendências futuras (SANTOS, 2004).

\section{CONSIDERAÇÕES FINAIS}

O presente trabalhou procurou fazer uma breve análise dos impactos ambientais gerados nos mananciais pelo crescimento urbano desordenado do Complexo Frei Calixto Baianão, no Município de Porto Seguro - BA. No qual ficou constatado que sua ocupação e criação foram desassistidas de um zoneamento urbano.

Contudo, fez-se necessário uma reflexão sobre o contexto histórico, pois, trata-se de uma população voltada para o trabalho no município originário da região cacaueira baiana, excluídas do uso e ocupação dos solos no plano diretor municipal. Percebeuse que com a expansão desse complexo de bairro de forma acelerada pela especulação imobiliária, a população mais carente foi sendo empurrada para área de proteção ambiental.

Desta forma, essa crescente expansão urbana vem provocando a degradação dos mananciais locais, resultando no assoreamento de córregos e rios impactando na vazão da rede de drenagem em estudo, podendo ocasionar perdas na captação e distribuição de água no Município.

RC: 103964

Disponível em: https://www.nucleodoconhecimento.com.br/meio-ambiente/crescimentourbano-desordenado 
Portanto, algumas medidas podem ser adotadas para mitigar e prevenir os impactos gerados pela contínua urbanização no Complexo Baianão, como a implementação de políticas públicas que visem a proteção da área de preservação permanente, equidade social e o melhoramento da mobilidade urbana, norteadas pelo zoneamento ecológico - econômico na escala de 1:100.000.

\section{REFERÊNCIAS}

AB'SABER, AZIZ NACIB. Domínios de Natureza no Brasil, Os - Potencialidades Paisagísticas. Atelie Editorial, f. 80, 2003. 160 p.

ARAUJO, Cristina Pereira de. Porto (in) Seguro: a perda do paraíso. Os reflexos do Turismo em sua paisagem. Orientador: Dr. Paulo Renato Mesquita Pellegrino. 2004. f. Dissertação (Mestrado em Arquitetura) - Faculdade de Arquitetura e Urbanismo, Universidade de São Paulo - USP, São Paulo, 2004.

. Um Porto Seguro para os Próximos 500 anos. Bahia análise \& Dados, Salvador, v. 15, n. 2-3, p. 145, 2005.

BRASIL. Planalto. Decreto n. 4.297, de 10 de julho de 2002, dispõe do Zoneamento Ecológico - Econômico. Diário Judicial Eletrônico. Brasília, 10 de julho de 2002. Disponível em: http://www.planalto.gov.br/ civil_03/decreto/2002/ d4297.htm\#: 200\%20art., que\%20lhe\%20confere\%200\%20art. Acesso em: 15 abr. 2021.

. Lei no 12.651 , de 25 de maio de 2012. Institui o novo código florestal brasileiro. Disponível em: < http://www.planalto.gov.br/ccivil_03/_ato20112014/2012/lei/l12651.htm>. Acesso em: 14 abr. 2021.

. IBGE - Instituto Brasileiro de Geografia e Estatística . Município de Porto Seguro. online, 2021. Disponível em: ibge.gov.br/brasil/ba/porto- seguro/panorama. Acesso em: 16 jan. 2021.

RC: 103964

Disponível em: https://www.nucleodoconhecimento.com.br/meio-ambiente/crescimentourbano-desordenado 
IBGE - Instituto Brasileiro de Geografia e Estatística. MAPA Domínios Hidrogeológicos da Bahia. online, 2019. Camada shapefile. Dimensões: 1: 5000 000. Disponível em: https://www.ibge.gov.br/geociencias /downloadsgeociencias.html. Acesso em: 20 jan. 2021.

CRISPIM, Diego Lima et. al. Impactos ambientais decorrentes do uso e ocupação desordenada do espaço urbano: um estudo de caso da cidade de Baixio/CE. Revista Verde de Agroecologia e Desenvolvimento Susten, Pombal, v. 9, n. 4, p. 44-49, 15 out. 2014. Disponível em: https://www.researchgate.net/publ ication/285347150_Impactos_ambientais_decorrentes_do_uso_e_ocupacao_desord enada_do_espaco_urbano_um_estudo_de_caso_da_cidade_de_BaixioCE. Acesso em: 10 abr. 2021.

CUNHA, Sandra Baptista da; GUERRA, Antonio José Teixeira. Avaliação e perícia ambiental. 8. ed. Rio de Janeiro: Bertrand Brasil, f. 131, 2007. 261 p.

GOOGLE. Google Earth - timelapse - Porto Seguro. online. Disponível em: https://earthengine.google.com/timelapsehttps://earthengine.google.com/timelapse. Acesso em: 16 mar. 2021.

MARRONI, Etiene Villela; ASMUS, Milton Lafourcade. Gerenciamento costeiro: uma proposta para o fortalecimento comunitário na gestão ambiental. Pelotas: Editora da União Sul-Americana de Estudos da Biodiversidade, f. 75, 2005. 149 p.

OBAIANÃO. Porto Seguro, ano 2013, 2 jun. 2013. Uncategories. Disponível em: https://www.obaianao.com.br/2013/06/o-baianao-nossa-historia.html. Acesso em: 18 mar. 2021.

PORTO SEGURO. Lei no 1511/19, Plano Diretor Municipal Participativo. Disponível em:<https://luigirotunno.com.br/wp-content/uploads/2019/01/PDMP_05122018_lei3 8_2018_Combinado.pdf $>$. Acesso em 18 de Set. 2021.

RC: 103964

Disponível em: https://www.nucleodoconhecimento.com.br/meio-ambiente/crescimentourbano-desordenado 
. PMMA - Plano Municipal de Conservação e Recuperação da Mata

Atlântica, n. 2. Diário Oficial. Porto Seguro. Disponível em: https://www.gamba.org.br/wp- content/uploads/2014/07/pmma_porto_seguro_v_2_ impressao1.pdf. Acesso em: 15 abr. 2021.

RIBAS, Otto. A sustentabilidade das cidades: Os instrumentos da gestão urbana e a construção da qualidade ambiental. Orientador. Brasília, f. 253, 2003. Tese (Mestrado em Arquitetura e Urbanismo) - Universidade de Brasília, Brasília, 2003.

ROCHA, Lurdes Bertol. A REGIÃO CACAUEIRA DA BAHIA - UMA ABORDAGEM

FENOMENOLÓGICA. Aracaju, f. 290, 2006. Tese (Organização e dinâmica dos espaços agrário e regional) - Universidade Federal de Sergipe, Aracaju, 2006. Disponível em: http://www.biblioteca.uesc.br/biblioteca/bdtd/732758856T.pdf. Acesso em: 15 mar. 2021.

SANTOS, Rozely Ferreira dos. Planejamento ambiental: teoria e prática. São Paulo: Oficina de Textos, f. 92, 2004. 184 p.

TOWNSEND, Colin R; BEGON, Michael; HARPER, John I. Fundamentos em Ecologia. Porto Alegre: Artmed Editora, v. 1, 2010. 576 p.

VERACEL CELULOSE. 2011. EIA/RIMA - Estudo de Impacto Ambiental - Relatório do Meio Físico. 538 p. (Não publicado). In BRASIL. Plano Municipal de Conservação e Recuperação da Mata Atlântica de Porto Seguro. Porto Seguro, 2014.

Enviado: Abril, 2021.

Aprovado: Dezembro, 2021.

RC: 103964

Disponível em: https://www.nucleodoconhecimento.com.br/meio-ambiente/crescimentourbano-desordenado 